\title{
La "nueva derecha" y su política exterior. Los primeros tres años de gestión del gobierno de Mauricio Macri
}

\author{
The "new right" and its foreign policy. The first three years of Mauricio \\ Macri's government
}

Laura María D’Alesio ${ }^{1}$

\section{Resumen}

En el marco de un nuevo tiempo histórico a nivel regional, marcado por el afianzamiento de gobiernos liberal-conservadores, este trabajo pretende investigar las principales medidas políticas tomadas por el gobierno de Mauricio Macri que den cuenta de la llegada al poder de una "nueva derecha" y su impacto en la política exterior. El estudio se enfoca en los cambios que se producen en las agendas político-institucional, económica, social e internacional en los primeros tres años de gestión de la nueva administración. El análisis muestra que la llegada al poder en Argentina de una nueva derecha genera modificaciones en la política exterior, cuyas principales manifestaciones son un nuevo posicionamiento ideológico, un claro giro primermundista y la consideración de la agenda externa como una especie de instrumento para lograr la transición hacia una economía globalizada. Estas modificaciones marcan además una creciente articulación entre política doméstica y política exterior.

Palabras clave: Mauricio Macri, nueva derecha, política exterior

\section{Abstract}

In the frame of a new historical time marked by the reinforcement of conservativeliberal governments this article aims to investigate the chief political measures taken by Mauricio Macri's government that leads to the establishment of a new right political ideology and how its measures impact on the foreign policy. The study is focused on the changes that take place in the economic, politicalinstitutional, social and international agendas of the first three years of the new government. The notes that follow attempt to show that the coming into power of

\footnotetext{
Recibido: 29 de septiembre de 2019 Aceptado: 17 de diciembre de 2019 Publicado: 20 de diciembre de 2019

${ }^{1}$ Licenciada en Relaciones Internacionales por la Universidad Nacional de Rosario (UNR). Investigadora del Grupo de Estudios sobre Negociaciones Comerciales Internacionales (UNR) e integrante del Observatorio Político Electoral (UNR). Rosario, Argentina. Correo electrónico: lauri_dalesio@hotmail.com
} 
a "new right" generates modifications in the foreign policy. Its main manifestations are a new ideological positioning, a clear first-world shift, and the consideration of the external agenda as a sort of instrument for achieving a transition to a globalized economy. These changes also develop a link between domestic and foreign policy.

Keywords: Mauricio Macri, new right, foreign policy

\section{Introducción}

En Sudamérica, los gobiernos que se encuentran en el poder suelen evidenciar elementos coincidentes que podrían dar cuenta de convergencias políticoideológicas a nivel regional. Iniciados los años ochenta, los diferentes países comenzaron a experimentar de manera generalizada la transición hacia regímenes democráticos. Luego, la década de los noventa se convirtió en el escenario de la hegemonía neoliberal. Finalizado este período, inició una corriente posneoliberalista que abarcó a los gobiernos de izquierda que se enfocaron en corregir las consecuencias negativas del Consenso de Washington y que se agruparon bajo la denominación de "giro a la izquierda".

En la actualidad, son muchos los académicos que subrayan la llegada de otro cambio de dirección en América del Sur, iniciado en 2015 e intensificado en 2016. Los partidos políticos de derecha y centroderecha no sólo han logrado una importante representación legislativa sino que también han conseguido conquistar el poder ejecutivo.

En el caso de Argentina, la gran novedad se produjo el 22 de noviembre del año 2015, cuando el por entonces empresario Mauricio Macri ganó las elecciones presidenciales por medio de una alianza partidaria - conocida como Cambiemos entre Propuesta Republicana (PRO), la Unión Cívica Radical (UCR) y la Coalición Cívica. Por primera vez en las urnas triunfó una derecha liberal que en Argentina nunca había llegado al poder a través de elecciones democráticas. La llegada de Mauricio Macri a la presidencia constituye, además, una de las principales expresiones del agotamiento del ciclo de gobiernos progresistas en la región y del inicio de un nuevo período liderado por gobiernos de perfil político conservador y defensores del liberalismo económico. Más aun, como lo plantea el historiador Enzo Traverso, no caben dudas de que la victoria de Donald Trump en las elecciones presidenciales estadounidenses y la aparición de partidos postfascistas de derecha en Europa, desplaza hacia la derecha el eje político del mundo (Traverso, 2018). Y si bien la Argentina aparece hoy al margen de estas tendencias políticas extremas y 
regresivas $^{2}$ que existen tanto en Europa como en Estados Unidos, el país no es para nada ajeno al debate y a la tendencia global.

Desde el inicio de la nueva gestión, el gobierno de Cambiemos buscó diferenciarse de la administración kirchnerista y diseñó una agenda de gobierno con profundos cambios en materia política, económica, social y también internacional. En este sentido, el cambio de gobierno trajo aparejado un cambio en la estrategia de desarrollo y, por ende, un cambio en la política exterior.

Para poder ampliar esta idea, en primer lugar se desarrollan las consideraciones conceptuales más importantes sobre la nueva izquierda, la nueva derecha y sobre la vinculación entre política exterior y modelo de desarrollo. Luego, se realiza una descripción del contexto regional actual y se puntualiza la llegada al poder de Mauricio Macri, la estrategia de desarrollo escogida por el gobierno y las principales medidas tomadas en el ámbito político-institucional, social y económico. Finalmente se aborda el cambio en la estrategia de inserción internacional de Cambiemos y los giros empíricamente observables.

\section{La nueva izquierda, la nueva derecha y el concepto de política exterior}

Para definir a la nueva izquierda y a la nueva derecha se parte de un elemento central aportado por el filósofo y politólogo Norberto Bobbio: derecha e izquierda son conceptos antitéticos, es decir, el uno existe gracias al otro. En términos prácticos, esto implica que la prominencia de uno de estos campos ideológicos no significa que el otro desaparezca y, por lo tanto, el peso relativo de la derecha y la izquierda varía a lo largo del tiempo y de los contextos propios de cada nación (Bobbio, 1995).

Dentro de esta perspectiva, se considera más rico en términos de análisis pensar que la izquierda, así como la derecha, constituyen un conjunto de procesos políticos y sociales enmarcados en contextos históricos determinados, que ponen en movimiento diferentes actores, luchas, intereses, proyectos políticos y alianzas. Es por ello que se define a los gobiernos a partir de contextos específicos y prácticas y agendas políticas propias.

En este marco, cuando se habla de izquierda se hace referencia a los gobiernos presentes en Sudamérica luego de la caída de la Unión Soviética y el bloque

\footnotetext{
${ }^{2}$ Destacan la aparición de un movimiento de derecha radical, Alternativa para Alemania, que llevó al Reichstag más de ochenta diputados; un gobierno austriaco integrado por una coalición de la derecha conservadora y la extrema derecha de origen neonazi; y la presencia de Marine Le Pen en la segunda vuelta de los comicios franceses, entre otras.
} 
socialista, que rebasan las preocupaciones clásicas de la izquierda tradicional asociadas a la emancipación, la reducción de la desigualdad económica y la lucha contra el imperialismo, para incluir nuevas agendas vinculadas a la etnicidad, el género, la raza y otras fuentes de desigualdad. Además, se caracterizan por la puesta en marcha de reformas sociales, que dan por sentado, en mayor o menor medida, ciertos principios de la economía de mercado (Calvo Salazar, 2009).

Por el otro lado, cuando se menciona a la de derecha se parte del concepto de "nueva derecha" aportado por José Natanson (2017) y se le añaden las ideas planteadas por otros autores como Gabriel Vommaro (2017), Ernesto Bohoslavsky y Sergio Morresi (2016) y el análisis de las medidas de políticas públicas llevadas a cabo en los primeros tres años de gobierno, para describir tentativamente a la "nueva derecha" como una derecha democrática, pero que muestra una inclinación permanente a producir hechos que disminuyen la calidad institucional de la democracia, dispuesta discursivamente, pero no en la práctica, a marcar diferencias económicas con la derecha noventista y socialmente no inclusiva.

Dentro de las agendas y estrategias propias, tanto de los gobiernos de izquierda como de los de derecha, cobra relevancia el modelo de desarrollo escogido, en tanto su alcance trasciende las definiciones puramente económicas y se convierte en un estructurante importante de la política exterior. Una definición de política exterior que se considera adecuada es la que da Roberto Miranda, en la cual enuncia que "la política exterior es el resultado de la asociación entre la percepción que las clases dirigentes tienen del mundo y los modos de inserción que estas clases pretenden para el Estado en el marco internacional” (Miranda, 2005, p.4). Esta definición no hace otra cosa que representar la coexistencia entre los factores nacionales y las variables externas en la formulación de la política exterior. Partiendo de esta conceptualización, este artículo plantea que dicha política contempla también, entre otras cosas, la estrategia de desarrollo elegida por el gobierno y que en función de la misma actúa en el plano internacional.

El modelo de desarrollo no es sino la manera en la que se articula la política y la economía en un contexto histórico determinado. A cada modelo de desarrollo le corresponde un modo de producción, de distribución de la riqueza y una estrategia de inserción internacional (Lorenzini, 2011, p.43 citado por Actis, Lorenzini, \& Zelicovich, 2017). La vinculación de la política exterior con la estrategia de inserción cobra diferentes valores y magnitudes según cada modelo de desarrollo.

\section{Relevamiento empírico: desde América del Sur a la Argentina de Cambiemos}


Siguiendo a Sebastián Santander (2009), la década del 2000 es sinónimo de cambio político para América Latina. La misma quedará en la memoria colectiva como la de los años del "giro a la izquierda" tal como los "80 y los "90 son considerados respectivamente como la "década perdida en términos económicos" y la época del "neoliberalismo".

La asunción de Luiz Inácio Lula da Silva en Brasil y de Néstor Kirchner en Argentina en 2003, el triunfo de Tabaré Vázquez en Uruguay en 2004, la victoria electoral de Evo Morales en Bolivia en 2005, de Bachelet en Chile ese mismo año y, de Rafael Correa en Ecuador al año siguiente, cerrando con la asunción de Lugo en Paraguay en 2008, son acontecimientos que contribuyeron a configurar un fenómeno regional que, desde el ámbito académico, se denominó giro a la izquierda o marea rosada (en inglés, <pink tide>). Nunca antes tantos países habían estado identificados con la izquierda al mismo tiempo. Llegando al poder ejecutivo a nivel nacional, obteniendo espacios legislativos o empoderándose a nivel de la sociedad civil, las izquierdas volvieron a cobrar protagonismo social y político en Sudamérica.

Sin embargo, entrada la segunda década del siglo XXI, el escenario regional es otro. Se instaló un gobierno neoliberal en Argentina; Brasil atravesó una crisis política que tuvo como consecuencia la destitución de Dilma Rousseff y la consiguiente presidencia, primero de Michel Temer y luego de Jair Bolsonaro- claros opositores del pensamiento progresista del PT-; en Venezuela el chavismo sufrió una importante derrota legislativa en 2015 y, aunque logró recuperarse en las elecciones regionales de 2017, sigue gobernando una sociedad con crisis estructural; se impuso el "no" en el referéndum llevado a cabo en Bolivia ${ }^{3}$, mediante el cual se proponía la reforma de la Constitución con vistas a un cuarto período de gobierno de Evo; en Ecuador, Rafael Correa logró que su sucesor, Lenin Moreno, conservara su poder, aunque por una diferencia mínima, y hoy cuestiona su giro a la derecha; y, en Uruguay, las encuestas sugieren una posible caída del Frente Amplio.

Si bien aún quedan naciones latinoamericanas gobernadas por líderes y partidos políticos de izquierda - como es el caso de Andrés Manuel López Obrador en México - esto no implica que le derecha sea insignificante en términos electorales. Además, durante el ciclo de gobiernos progresistas, los actores de esta tendencia no dejaron de existir. La derecha siguió teniendo una importante capacidad para influir en los gobiernos de turno, por ejemplo, mediante el financiamiento de campañas y

\footnotetext{
${ }^{3}$ En noviembre de 2017, el Tribunal Constitucional Plurinacional dictaminó que Evo Morales y todas las otras autoridades electas no tendrán ninguna clase de límite de mandatos, por lo que podrán buscar ser reelegidos en las urnas cuantas veces quieran, luego de que el actual presidente presentara un recurso abstracto de inconstitucionalidad contra la limitante constitucional a los mandatos consecutivos.
} 
el lobby ejercido sobre actores políticos y funcionarios públicos, así como también gracias a la difusión de sus ideas a través de los medios de comunicación de masas y al apoyo a tecnócratas que apoyaban políticas públicas cercanas a sus creencias (Rovira Kaltwasser, 2014).

El balance regional de fuerzas sugiere que, luego de una década de predominio de la izquierda, estamos frente al inicio de una transición hacia un nuevo tiempo histórico. "Quizá todavía resulte apresurado hablar de un nuevo ciclo, cuya consolidación dependerá de factores tan inescrutables como el desempeño de los nuevos gobiernos y los procesos electorales por venir" (Natanson, 2018, p.39). Sin embargo, es evidente que estamos frente a una nueva coyuntura política regional, en donde las fuerzas progresistas que gobernaron la región durante 10 o 15 años enfrentan el desafío del predominio de la derecha.

Siguiendo la propuesta de Constanza Moreira, "se comienza a hablar del "fin del ciclo progresista luego del triunfo de Mauricio Macri en Argentina en 2015 unido al triunfo de la oposición en Venezuela en las elecciones parlamentarias ese mismo año y, en 2016, el apartamiento de Dilma Rousseff en la presidencia de Brasil" (Moreira, 2017, p.2).

Mauricio Macri, líder de la coalición Cambiemos, llegó al poder luego de un sorpresivo triunfo en la segunda vuelta de las elecciones presidenciales, el 22 de noviembre del año 2015, sobre el candidato del entonces gobernante Frente para la Victoria, Daniel Scioli. Mauricio Macri no solo no provino de ninguna de las fuentes originarias del legado partidario - ni del peronista ni del radical - sino que su elección obedeció a la capacidad que tuvo para aglutinar en una alianza heterogénea a líderes, partidos y reclamos que se habían erigido contra los gobiernos kirchneristas.

La gestión presidencial de Cambiemos estuvo precedida por discursos con algunos conceptos y caracterizaciones sobre la situación política-institucional, social y económica de Argentina, que anticipaban, de cierta forma, el perfil que el Gobierno le quería dar a las políticas públicas.

Siguiendo las ideas planteadas por Anabella Busso, el eje de la campaña electoral que llevó a Mauricio Macri a la Casa Rosada fue la propuesta de "cambio", noción que atravesó cada uno de los discursos de campaña e incluso el nombre seleccionado por la alianza de gobierno. Esta idea señalaba no solo la necesidad de modificar lo realizado por los gobiernos del matrimonio Kirchner sino que también representaba el reclamo popular por una transformación politica. Tras la "anomalía populista”, el objetivo era entonces reconciliar a la Argentina con el mundo, y eso implicaba hacer las cosas de la manera en que las hacen en el mundo (Vommaro, 2017, p.236 citado por Busso, 2017) 
Mauricio Macri se propuso construir un nuevo Estado, en buena parte con características contrapuesta al proyecto que el kirchnerismo intentó erigir desde el año 2003. Y lo hizo en dos sentidos fundamentales. En primer lugar, en nombre del destierro de la excepcionalidad y el conflicto como lógica de ejercer el poder, eliminando la tan famosa grieta e intentando lograr unidad nacional. En diciembre de 2015, en su primer y breve discurso ante la Asamblea Legislativa, el nuevo presidente prometió la unión de los argentinos, "sacar el enfrentamiento del centro de la escena y poner en ese lugar el encuentro, el desarrollo y el crecimiento" (Macri, 2016a).

En segundo lugar, "producir una modernización económica y social que, en la visión del nuevo presidente y sus aliados, debería acercar al país a su tiempo histórico. La defensa de una concepción política republicana-liberal y de un programa económico-social de modernización de la gestión se convirtieron así en las dos banderas de PRO primero y de Cambiemos después” (Vommaro, 2017, p.234).

Se destacaba que las causas que explicaban el aislamiento internacional del país incluían un fuerte deterioro institucional, por lo que se propuso generar mayor confianza y para ello se planteó recuperar una agenda política cada vez más basada en una justicia independiente, un Estado al servicio de la gente y la defensa de la visión liberal-republicada del funcionamiento de las instituciones estatales. También en su discurso inaugural mencionó la necesidad de hacer especial énfasis en combatir la corrupción.

\footnotetext{
"Los bienes públicos pertenecen al conjunto de los ciudadanos y es inaceptable que un funcionario se apropie de ellos en beneficio propio. Voy a ser implacable con todos aquellos que de cualquier partido o filiación política, sean propios o ajenos, dejen de cumplir lo que señala la ley. No habrá tolerancia con esas prácticas abusivas. No hay principio ideológico que pueda justificarlas. Los bienes de la Argentina son para todos los argentinos y no para el uso incorrecto de los funcionarios". (Macri, 2016a).
}

La noción de cambio también incluía una meta más profunda: lograr un cambio en la cultura política de la sociedad argentina, destinado a borrar cualquier tipo de adhesión a lo que Mauricio Macri identificaba como populismo estatista vinculado directamente con el kirchnerismo (Vommaro, 2017, p.18). En sus discursos se observa el énfasis en la búsqueda del cambio de imaginarios y de sentido común, en el emprendedorismo, la meritocracia y el individualismo que, en conjunto, muestran la importancia que se le asigna a la lucha cultural y a la necesidad de una transformación refundacional.

En referencia a la batería de propuestas en materia de política social, ya en el Debate Presidencial de noviembre de 2015, Mauricio Macri argumentaba que su primer compromiso asumido frente a los argentinos era lograr una Argentina con pobreza 
cero y con igualdad de oportunidades (Macri, 2015c). Más aun, el 1ero de marzo del 2016, en la primera apertura de sesiones legislativas, estableció la pobreza cero como uno de los tres ejes de lo que sería su gestión. "Para salir de la pobreza necesitamos más trabajo y menos inflación, que es la que devora el salario de los que menos tienen. Mi obsesión, nuestra obsesión va a ser más y mejores trabajos y menos inflación” (Macri, 2016a).

En ese primer discurso el nuevo presidente argentino también reconocía la inversión en educación del kirchnerismo aunque argumentaba que la misma había sido mal ejecutada. Es decir, que la mayor cantidad de recursos no se había traducido en un aumento del aprendizaje de los alumnos y que las universidades creadas habían sido espacios de militancia política más que de excelencia académica. Se reconoció en varias oportunidades que otra gran línea de gestión sería la educación pública de calidad, entendiendo que esa era la verdadera herramienta para igualar oportunidades.

También se destacó la confianza en los docentes y los científicos del CONICET (Consejo Nacional de Investigaciones Científicas y Técnicas) para lograr la revolución en la calidad educativa. "Para eso tenemos algo maravilloso, son nuestros docentes, a los cuales tenemos que apoyar, tenemos que reivindicar, darles el prestigio social, pagarles bien y transformarlos realmente en esos agentes de cambio y entender que todos tenemos que estar comprometidos con una capacitación permanente" (Macri, 2015d).

En relación a la salud argumentaba algo similar. Especialmente cuando refirió al funcionamiento de PAMI (Programa de Atención Médica Integral). Lamentablemente nuestros abuelos en ese PAMI, mal gestionado y deficitario, como declaraba el presidente, recibían muchos de sus medicamentos gratis. En otra aparición pública declaraba que "todos tenemos la misma vocación, que es cumplirles a nuestros abuelos" (Macri, 2015d).

Finalmente, entre las propuestas económicas no sólo se criticó la calidad de la gestión económica durante los gobiernos de Cristina Fernández, sino también el modelo económico imperante en los doce años anteriores. En más de una ocasión, Mauricio Macri expresó que el problema en la Argentina no era el dólar sino el gobierno kirchnerista que no había parado de mentir, destruyendo la confianza en el país. La gestión actual intentó modificar la estructura estatal que se fue conformando durante el tan criticado ciclo kirchnerista, adecuándola a las necesidades de una transferencia de la regulación al "mercado" y poniendo en marcha no solo una nueva política económica, sino un nuevo modelo de desarrollo. En este marco, se adelantaron un conjunto de medidas económicas identificadas comúnmente con el neoliberalismo (Busso, 2017, p.2). Se buscó torcer el rumbo de 
la economía y llevarla hacia modelos más afines a la visión de los managers, produciendo una sociedad de mercado moderna, globalizada y afín a un capitalismo cuyo principal motor es el libre flujo de inversiones.

Sin embargo, la Argentina discursiva del presidente Mauricio Macri chocó con el país real. Habiendo finalizado su tercer año de gobierno, en la dimensión política institucional, la nueva administración adolece de transparencia y legitimidad, ha sido salpicada por importantes casos de corrupción y ha mostrado diversos intentos de imponer reformas regresivas en diferentes áreas de la administración pública.

El presidente de la Nación, en su discurso de apertura de sesiones ordinarias del Congreso destacó los logros de su gestión en materia de transparencia gubernamental y señaló que "Argentina mejoró las posiciones y calificaciones del Índice de Transparencia Internacional" (Macri, 2018a). Efectivamente, en los últimos años Argentina ha avanzado en ciertos aspectos en materia de transparencia y lucha contra la corrupción como con la nueva Ley de Derecho de Acceso a la Información Pública, la Ley de Colaborador Eficaz y la Ley de Responsabilidad Penal de las Personas Jurídicas. De todos modos, vale la pena destacar que, a pesar de las mejoras, el país aún se encuentra entre las naciones percibidas como altamente corruptas. Es por ello que el anuncio no dejó de sorprender, enmarcado en un gobierno signado por varios casos de corrupción ${ }^{4}$.

En diciembre de 2015 Mauricio Macri también colocó dentro de las 100 prioridades, en el marco de la modificación de la Administración Nacional Pública, la necesidad de actualizar y modernizar la gestión estatal. Bajo el argumento de que durante los gobiernos kirchneristas hubo un excesivo incremento del empleo público con mecanismos de ingresos poco transparentes, el puntapié inicial de la oleada de despidos se produjo en el Estado, como parte de este proceso "modernización". Sin embargo, al cabo de muy poco tiempo se recuperó el nivel de empleo público de partida, se incrementaron, y de manera significativa, los cargos con responsabilidad funcional, mientras se redujo a la mitad el número de Ministerios y otros se fusionaron o pasaron al rango de Secretaria (Comisión Estado y Administración Pública en el Proyecto Nacional, 2017, p.12).

\footnotetext{
${ }^{4}$ Entre estos destacan las sociedades offshore del propio Presidente y otros funcionarios y allegados a la familia Macri en el marco de los Panamá Papers; el blanqueo de capitales a familiares de funcionarios; el escándalo por el intento de auto-condonación de la deuda millonaria con el Correo Argentino - firma que pertenecía a Franco Macri y que según la acusación habría sufrido un intento de vaciamiento - ; el embargo a Ángelo Calcaterra, primo de Macri, por supuestas coimas en la obra de soterramiento del Sarmiento; la concesión de rutas aéreas a Avianca; la renuncia de Díaz Gilligan como subsecretario de la presidencia después de que le encontraron más de un millón de dólares sin declarar en Andorra; y las presuntas coimas recibidas por Gustavo Arribas, el jefe de la AFI, que investiga la justicia brasileña, entre otras.
} 
En la dimensión social, Cambiemos ha generado una red de contención mínima antes que una estrategia de ampliación de derechos sociales. Se produjo un desmontaje silencioso de diferentes planes y programas, a excepción de la extensión del beneficio de las asignaciones familiares a los hijos de los monotributistas. Al mismo tiempo, el presupuesto para la educación, la cultura y la salud disminuyó en términos reales.

Tampoco se logró disminuir los índices de pobreza. El INDEC informó en septiembre de 2018 que, en la primera mitad de de ese año, la pobreza fue del 27,3\%, lo que significa que cerca de 12 millones de argentinos vivía a comienzos de año con ingresos por debajo de la línea de bienes y servicios básicos (Instituto Nacional de Estadística y Censos, 2018).

Entre otras subejecuciones que son parte de la agenda real de la nueva administración, uno de los ejemplos más notorios fue el del PAMI, que recortó la cobertura de medicamentos para sus afiliados, eliminó programas de prevención y limitó la cantidad de medicamentos que entrega a los centros de jubilados. (Comisión Estado y Administración Pública en el Proyecto Nacional, 2017, p.19).

Cambiemos también ha tenido una política mucho menos activa, en comparación con sus predecesores, en lo respectivo a la promoción y defensa de los derechos humanos y, en relación al manejo de la protesta social, habilitó una estrategia de mano dura, ignorando los avisos de los organismos internacionales de Derechos Humanos frente a la detención de Milagros Sala o la propuesta de fijar un nuevo régimen de justicia penal juvenil.

En la dimensión económica, la administración macrista ha adoptado un enfoque claramente ortodoxo, centrado mayoritariamente en metas de inflación, apertura comercial, liberalización de los movimientos de capitales y desregulación, y no así en el desarrollo de políticas de redistribución de ingresos y medidas para lograr el pleno empleo. Bajo el argumento de "reinsertar a Argentina en el mundo", Cambiemos devaluó la moneda en un $100,2 \%{ }^{5}$, liberalizó el comercio en detrimento de las Pymes, ejecutó la apertura del movimiento de capitales, desreguló ciertos mercados, aplicó una política monetaria instrumentada en favor de la especulación financiera y trató de debilitar a Aerolíneas Argentinas ante la opinión pública para que la totalidad del mercado aeronáutico sea absorbido por empresas low cost. En este sentido, los primeros y acelerados pasos de la nueva política económica constatan la presencia de fuertes cambios cercanos al neoliberalismo.

Según los últimos datos publicados por el Ministerio de Producción y Trabajo de la Nación, en septiembre de 2018 hubo 6,22 millones de asalariados formales en el

\footnotetext{
${ }^{5}$ Según el Informe del Observatorio de Políticas Públicas de la Universidad Nacional de Avellaneda (UNDAV), hasta septiembre 2018 la devaluación del peso argentino fue de un 100,2\%, posicionándose como el país con la mayor devaluación monetaria del mundo.
} 
sector privado, cifra que no solo es inferior al pico absoluto de marzo de 2018 (cuando había 61.000 empleos más bajo esta modalidad), sino que incluso se encuentra por debajo de noviembre de 2015 (Secretaría de Trabajo y Empleo Ministerio de Producción y Trabajo, 2018). Además, según la Asamblea de Pequeños y Medianos Empresarios, desde 2016 a agosto de 2018 cerraron más de 7.000 Pymes.

"Para la población en general, esto implica en lo inmediato más pobreza y mayor desempleo. Para el conjunto de las Pymes, significa una constante pérdida de rentabilidad por el sustancial deterioro de la demanda del mercado interno". (Asamblea de Pequeños y Medianos Empresarios, 2018). Asimismo, se debe sumar el impacto negativo que generan los aumentos de costos de insumos dolarizados.

Además, en 2018 volvió a dispararse la inflación. Según el INDEC, en los primeros diez meses del 2018 la inflación fue del 39,5\% en todo el país, superando la medición de todo el año 2016 y 2017. Teniendo en cuenta el Relevamiento de Expectativas del Mercado (REM), la inflación interanual a diciembre de 2018 rondaría el 47,5\%: siendo la inflación más alta de los últimos 27 años (Resultado del Relevamiento de Expectativas de Mercado, 2018).

Finalmente, no es menos relevante que Cambiemos partió de la presunción de que, una vez logrado el equilibrio en las cuentas internas y externas, se restauraría la confianza internacional y por ende el nivel de inversión extranjera en el país, lo cual no sucedió. Ello es ciertamente discutible porque, si bien las medidas implementadas suponen un aumento de la rentabilidad y por ende un incentivo a la inversión, el aumento de la tasa de interés y la caída de la demanda interna ejercen presiones contrarias a la inversión privada $\mathrm{y}$, por otro lado, obliga al gobierno a buscar financiamiento mediante la toma de deuda, en un escenario en el que los mercados externos dan indicios de contracción y ralentización del crecimiento.

\section{La política exterior de Cambiemos (desde diciembre de 2015 hasta diciembre de 2018)}

De la definición de política exterior se extrae que percepción y acción son los dos ejes fundamentales de dicho concepto. En este sentido, el gobierno de Mauricio Macri comenzaría retomando las visiones más favorables del escenario global a la hora de percibirlo, y definir e implementar su agenda internacional (Frenkel, 2016). La idea de generar un cambio y rechazar los proyectos populistas, que permeó toda la campaña electoral del nuevo Presidente, también se vio reflejada en la agenda externa. Esta propuesta se unió a la idea de volver al mundo como única alternativa 
para el pais, lo que de hecho presuponía que durante las administraciones anteriores Argentina se encontraba aislada.

Cambiemos es un proyecto que propone la "normalidad". La idea central es normalizar un país en un mundo ya normalizado y la normalidad para Cambiemos es la hiperglobalización, por lo tanto el objetivo es lograr una plena inserción en dicho proceso. Quizás, como señala Anabella Busso, el ejemplo más claro de esta tendencia se encuentra en los criterios señalados por el Presidente a la hora de seleccionar a la Ing. Susana Malcorra como la primera canciller de su gestión, cuando explicó que, además de su experiencia en la ONU, deseaba que la tarea fuese desempeñada por alguien que había vivido por más de veinte años en el exterior y fuese capaz de explicar cómo nos veían desde afuera (Busso, 2017, p.4). Además, la elección de una canciller moderada auguraba cierto gradualismo en este campo, en consonancia con el tenor del proyecto político interno.

Sin embargo, Susana Malcorra duró tan solo diecisiete meses al frente del Ministerio de Relaciones Exteriores y Culto. En mayo de 2017, rodeada por Mauricio Macri y por el jefe de gabinete, Marcos Peña, oficializó su renuncia alegando problemas personales y desató todo tipo de especulaciones sobre su partida. Su gestión quedó marcada por la detención de Milagro Sala, la cercanía con Michel Temer, su tibieza frente a Venezuela, el fracaso de su candidatura a Secretaria General de la Naciones Unidas y una salida del Gabinete confusa e inesperada.

Malcorra fue reemplazada por Jorge Faurie, un diplomático de carrera que sumó una década de promociones bajo la gestión de Guido Di Tella, el famoso ministro de relaciones exteriores que Carlos Menem mantuvo entre 1990 y 1999, para protagonizar la política bilateral con Estados Unidos conocida como "relaciones carnales"6.

Según Fulvio Pompeo, en base a la percepción de un mundo globalizado, el desafío principal de la política exterior del gobierno fue, desde un principio, poder capitalizar las oportunidades que ofrecía el mundo para avanzar en el logro de las metas nacionales (Pompeo, 2015). Fue Susana Malcorra quien, en una entrevista cercana a su salida, brindada en el programa "Odisea Argentina" argumentó que "el primer objetivo que el Presidente se planteó fue la eliminación de la pobreza. Ese primer objetivo marcó fuertemente la gestión de la Cancillería, porque le puso un

\footnotetext{
${ }^{6} \mathrm{El}$ contenido fundamental de dicha política consistió en seguir los postulados del realismo periférico, acoplarse con Estados Unidos y disminuir al mínimo las posibilidades de trazar políticas que contradijeran los intereses de dicho pais. Este acoplamiento a los Estados Unidos llevaría, asimismo, a afirmar la pertenencia irrestricta de Argentina al mundo occidental y, en este sentido, Carlos Menem no escatimó en gestos de confianza: se enviaron naves a la guerra del Golfo, se desmanteló la iniciativa del misil Cóndor y de diversos proyectos de industria aeroespacial, se concretó el retiro del Movimiento de Países No Alineados, se rubricaron múltiples acuerdos con Washington, y se consiguió la designación de Argentina como "aliado extra OTAN", entre otros.
} 
sesgo muy fuerte en lo económico. No era suficiente salir a reconquistar los vínculos con el mundo sólo desde lo político, sino también desde lo económico” (Malcorra, 2017a).

En una clara intención de atraer capitales e inversiones, la inserción de Argentina en el mundo se expresó a partir de dos ejes principales: los socios elegidos para vincularse en el sistema global y la agenda priorizada con dichos socios. Bajo la idea de "desideologizar" la política exterior, se buscó un cambio rápido en la forma de moverse internacionalmente, dejando atrás el tejido de alianzas, inversiones y valores vinculados a la integración regional y la cooperación con sus pares del Sur para abrirse al mundo y generar así el clima de negocios que la gestión ministerial de los CEO pretendía.

Este giro en las relaciones internacionales intentó ser pragmático y predominantemente económico. El gobierno mostró tener una autopercepción de país del Tercer Mundo - consciente de su lugar como país en desarrollo - pero que debía relacionarse principalmente con los grandes del globo. Desde el inicio de su gestión, Mauricio Macri privilegió una clara orientación primermundista y una inserción occidental, considerando la agenda externa como una especie de instrumento para lograr la transición hacia una economía globalizada.

Así, se estructuraron nuevas fuerzas e intereses que reorientaron la estrategia internacional elegida para el país y su relación con el modelo de desarrollo escogido a nivel interno, o pensando en retrospectiva, haciendo extensiva la agenda económica interna al plano internacional. En los primeros tres años de la nueva administración se concretaron varios cambios empíricos que dan cuenta de ello. a) La selección de los Estados más poderosos como vínculos bilaterales prioritarios entre los que se destacan Estados Unidos y algunos Estados europeos como Alemania, España, Italia, Gran Bretaña y Francia; b) la mejora de las relaciones con el sector financiero internacional (FMI) y otras instancias multilaterales (Davos, G20 financiero, OMC); y favorecer los vínculos con los países vecinos que tienen una propuesta de inserción internacional semejante, repensando la integración regional en clave comercial y encabezando una postura crítica frente al caso venezolano, son indicadores planteados por Anabella Busso (2017 a y b; 2018) ${ }^{7}$ para dar cuenta de una inserción marcadamente pro occidental y que, en este caso, se toman y se desarrollan -en los apartados 4.1, 4.2 y 4.3- para también explicar el nuevo posicionamiento ideológico de Argentina. Además, el relanzamiento de la relación estratégica con el gigante chino, es una variable que muestra cómo la

\footnotetext{
${ }^{7}$ En su artículo titulado "El rol de los Estados Unidos en el diseño de política exterior del gobierno de Mauricio Macri. Conceptos básicos para su análisis”, la autora también menciona otras variables que también enriquecen la lógica de una conducta pro- occidental como el reposicionamiento de países en la agenda de Política Exterior más allá de su ubicación geográfica, los criterios para orientar el comercio exterior y las políticas de Derechos Humanos, Seguridad y Defensa, entre otros.
} 
agenda externa - más allá de la orientación ideológica y la adhesión a los principios occidentales - se convierte en un instrumento para lograr una mejor inserción en un mundo globalizado.

\subsection{Priorizar vínculos bilaterales con los países poderosos del globo, entre los que se destacan Estados Unidos y algunos Estados europeos como Alemania, España, Italia, Gran Bretaña y Francia.}

Desde el comienzo de la nueva administración, se produjo un realineamiento de las relaciones bilaterales dando prioridad al gigante del norte. El vínculo con Estados Unidos "se transformaría en un eje central de la estrategia externa del gobierno y la llave fundamental de la tan proclamada vuelta al mundo" (Frenkel, 2016, p.4) En este marco, Mauricio Macri recibió en marzo de 2016 una visita de Estado del por entonces presidente norteamericano, Barack Obama. El nuevo mandatario argentino se refirió a dicha visita como un gesto de afecto y amistad en un momento en que la Argentina emprende un nuevo horizonte, un nuevo cambio. En la previa de la reunión, y en un intento de relanzar las relaciones bilaterales, funcionarios de ambos países rubricaron acuerdos en materia de seguridad, de cooperación para prevenir el crimen organizado y de comercio para atraer inversiones (Cué, 2016).

Sin embargo, en el contexto de las elecciones presidenciales de 2016 en Estados Unidos, Cambiemos partió de una hipótesis equivocada al inclinarse "apresuradamente" por el triunfo de Hillary Clinton. No obstante, las elecciones de noviembre implicaron volver a empezar (Busso, 2017). El triunfo de Donald Trump eliminó además el proyecto del Trans-Pacific Partnership ${ }^{8}$, y la posibilidad de Argentina de ser un Estado miembro y tener mucha más presencia en el Pacifico. Ahora bien, la mala lectura que realizó el gobierno argentino no imposibilitó, a posteriori, la firma de acuerdos bilaterales y el apoyo recibido por el nuevo presidente norteamericano. Pese a la incertidumbre que se generó sobre las consecuencias que podría tener el apoyo explícito que el gobierno de Cambiemos le brindó a la candidata contraria durante la campaña electoral, las visitas oficiales y los gestos políticos del republicano continuaron.

Siguiendo esta política de encuentros - y desencuentros-, la visita de Trump a la Argentina, previa a la apertura oficial del G20, fue la primera que realizó el mandatario a un país latinoamericano desde que asumió y la séptima de un jefe de Estado de Estados Unidos a la Argentina. A pocas horas de su llegada, el Servicio de Inspección de Sanidad Animal y Vegetal del Departamento de Agricultura Norteamericano confirmó que, tras 17 años, nuestro país volvería a exportar carne

\footnotetext{
${ }^{8}$ Es un tratado de libre comercio entre varios países de la Cuenca del Pacífico que aborda una variedad de materias de políticas públicas, firmado el 4 de febrero de 2016 en Auckland, Nueva Zelanda. Fue la pieza central del pivote estratégico del presidente Barack Obama en Asia.
} 
fresca. Sin embargo, dicho acuerdo fue de reciprocidad, en tanto las exportaciones estadounidenses de carne vacuna tienen un acceso ilimitado al mercado argentino, se estableció un límite de 20.000 toneladas para la venta de carne argentina en Estados Unidos.

Ambos mandatarios se encontraron dos veces más fuera del país y tras una de esas reuniones el presidente norteamericano declaró que Mauricio Macri era un buen amigo desde hacía veinticinco años y que se sentía muy cómodo respaldándolo y respaldando el ingreso de Argentina a la Organización para la Cooperación y el Desarrollo Económicos (OCDE). Sin embargo, la confianza de Trump en Macri más que plasmar una larga amistad, garantiza que no se cambien las reglas de juego.

Como sostiene Anabella Busso (2017), si bien la gestión de Cambiemos se propuso recomponer el vínculo con Trump acercándose a la administración republicana, lo cierto es que lo logró en términos formales y de dialogo político, pero aún no en términos económicos. Los resultados de la balanza comercial así lo demuestran. En los últimos tres años no ha habido un aumento considerable en las exportaciones y el saldo negativo de la balanza se ha incrementado, rondando los 3.000 millones de dólares, según los datos que se encuentran disponibles en el sitio web de la Organización Mundial del Comercio. Aun así, ante la posibilidad de que el gobierno de Cambiemos pierda popularidad por la dura crisis económica, el dirigente norteamericano lo sostiene a través del préstamo del Fondo Monetario Internacional (FMI)

También, como una manera de desplegar su estrategia de inserción internacional primermundista, Susana Malcorra concretó visitas al país de Presidente y Primeros Ministros de los Estados centrales y, simultáneamente, coordinó los viajes de Mauricio Macri a esos destinos. Desde un comienzo se hizo un esfuerzo por mostrar esta nueva imagen y, tan sólo en el primer año de mandato, Mauricio Macri recorrió trece países y realizó quince reuniones bilaterales.

Además, Federica Mogherini, la Alta Representante de la Unión Europea para la Política Exterior, dio un fuerte respaldo al nuevo Presidente argentino y a su gestión. Mauricio Macri recibió también al presidente del Banco Europeo de Inversiones, Werner Hoyer, quien expresó su abierto apoyo al país y a las reformas emprendidas por la nueva administración (Presidente de la Euro cámara felicita a Macri por mejora de relaciones Argentina-UE, 2016).

Gran Bretaña, la otra potencia con la cual el país pretendía normalizar relaciones, desde un principio estuvo concentrada en cómo iba a resolver el enredo económico que le generaría la conclusión del Brexit. Aun así, se lograron ciertos avances, entre 
ellos destaca una declaración conjunta de septiembre de 2016, en donde se estableció la necesidad de promover el intercambio comercial y más vuelos a las islas Malvinas (Ministerio de Relaciones Exteriores y Culto, 2016a), aunque se obviaron las protestas por la existencia de una base militar británica.

\subsection{Disminuir la tensión con los organismos multilaterales de crédito (FMI) y mejorar el posicionamiento de Argentina en los ámbitos multilaterales (Davos, G20 financiero, OMC)}

Puede decirse que desde la llegada al poder de Cambiemos, Argentina también ha ganado presencia en los espacios multilaterales donde se discuten muchas de las reglas de la economía política y se sientan las bases de la gobernanza mundial. "Esto ha sido considerado por el gobierno como un éxito en la "vuelta al mundo. Al respecto, se destacan la realización en Argentina del Foro Económico Mundial (FEM), la confirmación para auspiciar la Undécima Conferencia Ministerial de la Organización Mundial del Comercio (OMC), y la designación para ejercer la presidencia del G20 y para ser la sede de su reunión anual. Junto a ello, se agrega la solicitud argentina para ingresar a la Organización para la Cooperación y el Desarrollo Económicos (OCDE) (Castaño, 2018, p.3).

Al mismo tiempo que Argentina comenzó a mostrarse moderna, convincente, previsible y adecuada a los tiempos internacionales que corren, logró un acuerdo con los fondos buitres que le permitió comenzar a tomar deuda externa. El pago de deuda no reestructurada fue otra de las estrategias del gobierno para acceder al crédito internacional.

\footnotetext{
El acceso al crédito internacional estaba parcialmente dificultado por el conflicto que mantenía el Estado argentino con los llamados "fondos buitre". El gobierno de Cambiemos inició una negociación a comienzos de año con esos fondos, que culminó con la aprobación de una ley en el Congreso que derogaba leyes anteriores que bloqueaban un acuerdo y con la autorización para tomar deuda en el exterior por 12.500 millones de dólares. (Vommaro, 2017, p.236).
}

En abril del año 2016, el gobierno de Mauricio Macri transfirió US\$ 9300 millones para cancelar los acuerdos cerrados con bonistas minoritarios, incluidos los acreedores italianos representados por Nicola Stock, y con fondos buitre, entre ellos, NML Capital, de Paul E. Singer, líder de la ofensiva judicial contra la Argentina en la justicia norteamericana, que se quedó con aproximadamente US\$ 2426 millones. 
Tras el fallo de la Cámara de Apelaciones de Nueva York, el presidente argentino explicó que "se trató de un hito importante, el cierre de una etapa que terminó después de más de una década de aislamiento y conflicto". Además, destacó que "logramos salir del default y abrir una puerta al mundo" y aseguró que habilitará la llegada de nuevas inversiones en el país y mayores exportaciones. Por su parte, el entonces ministro de Hacienda, Alfonso Prat-Gay, señaló que "este arreglo nos volvió a conectar con el mundo".

En este marco, quince años después de que Néstor Kirchner cancelara la deuda con reservas del Banco Central, el FMI regresó a Argentina para auditar sus cuentas nacionales. El gobierno argumenta que la intervención del FMI lo respalda en los mercados internacionales y que su dinero es más barato que cualquier otro. Lo es, quizás, en términos económicos, pero suele ser muy caro en términos políticos en tanto impone decisiones al Estado y genera un rechazo interno brutal.

\subsection{Favorecer los vínculos con los países vecinos que tienen una propuesta de inserción internacional semejante, repensar la integración regional en clave comercial y encabezar una postura crítica frente al caso venezolano.}

Bajo la idea de "desideologizar" la política exterior, también se buscó operar una transformación rápida en la inserción regional del país, dejando de lado los valores vinculados a la integración regional y a la cooperación Sur- Sur.

En este marco, los cambios en la política exterior imprimidos por el nuevo gobierno tendrían necesariamente su expresión en la política de integración regional. En este sentido, un punto central de análisis es el rol que el gobierno de Mauricio Macri le ha asignado a su vecindario geográfico en un marco de crisis de los procesos de integración regionales, especialmente del Mercosur. (Castaño, 2018, p.5).

Al igual que los gobiernos que le precedieron, desde el primer momento Mauricio Macri postuló a la región como un eje central de su política exterior y como un puntapié para lograr una mayor proyección internacional. En este sentido el Mercosur - y al tan ansiado acuerdo con la UE - y a la Alianza del Pacífico ${ }^{9}$ se convertirían en las instancias regionales privilegiadas por Cambiemos (Argentina prioriza al Mercosur en su política exterior, 2016).

En un sentido contrario, "y en sintonía con la idea de lograr un mejor posicionamiento en las cadenas globales de valor, las agendas políticas y

\footnotetext{
${ }^{9}$ La Alianza del Pacífico nació como una iniciativa económica y de desarrollo entre cuatro naciones de América Latina: Chile, Colombia, México y Perú. Desde ese momento hasta la fecha, la Alianza se ha convertido en el eje de una nueva forma de hacer negocios en el continente. Se define como un mecanismo de articulación política, económica, de cooperación e integración que busca encontrar un espacio para impulsar un mayor crecimiento y una mayor competitividad de las cuatro economías que la integran.
} 
multidimensionales de la integración se irían diluyendo. Instancias como la UNASUR y la CELAC perderían protagonismo, mientras que el Mercosur buscaría ser reconfigurado a la luz de un modelo de inserción internacional centrado en las agendas económicas y comerciales" (Frenkel, 2016, p.2).

Por el lado de los vínculos con Brasil, como bien explica Castaño, "con el objetivo de fortalecer las relaciones comerciales y reafirmar el compromiso por el Mercosur, este país fue el primer destino de visita de Mauricio Macri como presidente electo, siendo recibido por la presidenta Dilma Rousseff. Sin embargo, una vez consumado el proceso de impeachment hacia la ahora ex-mandataria, Argentina fue el primer país que apoyó al nuevo líder del ejecutivo Michel Temer”. (Castaño, 2017, p.5). Tanto Mauricio Macri como Michel Temer se mostraron interesados en estrechar los vínculos comerciales de ambas naciones y del Mercosur con la Alianza del Pacifico.

Por el lado de Venezuela, en el medio de una profunda crisis política, social y económica, el presidente Nicolás Maduro se ha mantenido en el gobierno. Al respecto, Argentina no sólo ha apoyado la suspensión de Venezuela tanto en el Mercosur como en la Organización de los Estados Americanos (OEA), y ha abogado por la convocatoria a elecciones y la liberación de los presos políticos (Castaño, 2018), sino que también ha expresado que no reconocería el resultado de las elecciones. Esta postura no sólo ha demostrado un viraje en relación a los acontecimientos que tienen lugar en otros países que sufren crisis internas importantes, tales como Brasil, sino que se ha visto en cierta medida contrarrestada por la situación de la dirigente social kirchnerista Milagro Sala.

Desde el comienzo de su mandato, Mauricio Macri encabezaría junto a Brasil, la ofensiva contra la Venezuela de Nicolás Maduro, que pondría en cuestionamiento la idea de una política exterior "desideologizada".

\subsection{Apostar a la relación estratégica con China}

La intención inicial de privilegiar acuerdos con países de mayor apertura de fronteras aduaneras - expresada en el ingreso de Argentina como miembro observador a la Alianza del Pacífico - así como en el avance hacia la firma de un tratado de libre comercio con la Unión Europea, parecía dar cuenta de un giro radical de la política exterior de Argentina. Sin embargo, los inesperados resultados de las elecciones presidenciales norteamericanas, así como las dificultades para avanzar en el tratado con la Unión Europea, llevaron al gobierno de Mauricio Macri a privilegiar la ya instalada alianza estratégica con China.

Fue el mismo ministro del interior, Rogelio Frigerio, quien terminó por reconocer que "todo es de una sensibilidad muy grande, porque Argentina tiene una muy 
buena actitud inter. acional. Estados Unidos es nuestro aliado estratégico en la región y reconocemos el lugar mundial de China que es nuestro principal socio comercial" (Argentina y China: una relación compleja con el primer inversor y el principal mercado, 2018).

Como plantea Anabella Busso, la decisión de concentrar la política exterior sólo en las potencias occidentales o en países con una orientación político-económica semejante generó que, frente al entorpecimiento del escenario internacional, Cambiemos tuviese que modificar su vinculación con China en búsqueda de nuevos socios y nuevas inversiones (Busso, 2016, p.13).

Desde la asunción del presidente electo, las relaciones bilaterales entre China y Argentina han pasado por momentos de mayor tensión y momentos de mayor afianzamiento (Lin Hua, 2017). China es el segundo destino de las exportaciones argentinas, luego de Brasil y por delante de Estados Unidos. El gigante asiático es el primer comprador de carne argentina en el mundo y sus importaciones de soja se expanden a raíz de la guerra comercial con Estados Unidos. Además, es el máximo inversor de Argentina y, si se excluye al FMI, también su principal acreedor.

Si bien se han registrado enormes avances aún subsisten serios problemas, relacionados directamente al vínculo estratégico que la nación también mantiene con los Estados Unidos. En este sentido, se puede destacar la decisión de Argentina de no integrarse oficialmente a la iniciativa de la Ruta de la Seda ${ }^{10}$ o, como sostienen algunos analistas, la baja a las centrales nucleares. No obstante, el Canciller Jorge Faurie se ocupó de desmentir estas noticias y, por ejemplo, justificó la suspensión de la central asiática por motivos presupuestarios.

\subsection{A modo de síntesis}

Con mayor gradualismo en algunos casos y con mayor premura - y errores de percepción - en otros, lo concreto es que la administración de Mauricio Macri descongeló las relaciones con los socios tradicionales, dio un mensaje de "apertura" y "normalización" al mundo y priorizó un ámbito que le resulta familiar a un ex vicepresidente ejecutivo de empresas multinacionales.

También a través de diferentes iniciativas internacionales logró sentarse en la mesa de los grandes, lo cual le trajo aparejados mayores compromisos, mayores exigencias, y mayores reglas que respetar. Y si al plan de negocios e inversiones del

\footnotetext{
${ }^{10}$ Es un proyecto político-económico que Xi Jinping propuso en septiembre y octubre de 2013 en sus respectivos viajes a Asia Central y al Sudeste Asiático. El proyecto parte de la reconstrucción de la antigua ruta de la seda y la creación de una ruta marítima paralela, de aquí el nombre de "Franja y Ruta". El proyecto afecta a 60 países, el 75\% de las reservas energéticas conocidas al mundo, el 70\% de la población mundial y generaría el 55\% del PIB mundial. El gobierno chino tiene previsto invertir unos 1,4 billones de dólares. Se trataría de un cinturón económico.
} 
macrismo se le suma un escenario internacional poco favorable y muy impredecible debido al proceso globalizador en crisis, el panorama no se presenta muy cercano a lo plasmado en los discursos de campaña.

En términos de política regional, el gobierno de Mauricio Macri es parte de la ola de gobiernos de centro-derecha y derecha en Sudamérica y, como ha dejado en claro, una de las principales expresiones del agotamiento del ciclo de gobiernos progresistas en la región. Sus críticas cada vez mayores a la Venezuela del presidente Nicolás Maduro, tanto en instancias regionales como multilaterales; el acercamiento a Michel Temer y, posteriormente a Jair Bolsonaro; y su incorporación como miembro observador a la Alianza del Pacifico ejemplifican su creciente interés por cambiar la inserción regional del país.

Por último, que un gobierno como el de Cambiemos haya continuado y profundizado un vínculo iniciado por un gobierno de signo opuesto - como es el establecido China - revela que estamos ante una alianza valiosa entre ambos países pero que descansa, en mayor medida, en la capacidad china de encarar sus objetivos por medio de estrategias de largo plazo y una actitud pragmática e inteligente.

\section{Conclusiones}

El triunfo de Mauricio Macri en la segunda vuelta de las elecciones presidenciales marcó un profundo giro en la política argentina. La agenda política de Cambiemos nos permite ver el accionar de un gobierno surgido de una estrecha votación electoral, que tuvo el desafío de reorientar las políticas públicas en virtud de un nuevo proyecto de país, mientras lidiaba con un cambio ideológico a nivel regional, una etapa de transición e incertidumbre a nivel global y una economía nacional en crisis.

Resulta indiscutible el giro copernicano en el tipo de régimen y la forma de Estado, transitando de un gobierno nacional y popular a otro de claro carácter liberalconservador. Todas las medidas tomadas en el plano político-institucional, social y económico poseen el objetivo común de redefinir la naturaleza del Estado y mostrar una transformación radical respecto al proyecto kirchnerista.

A pesar de que el gobierno públicamente intenta alejarse del gobierno menemista y se niega a ser caracterizado como un gobierno neoliberal que impulsa un modelo de desarrollo ortodoxo, un breve repaso de sus principales acciones en materia de política interna lo acercan al mismo: devaluación de la moneda, concentración del ingreso, reducción de presupuestos en salud, educación y tecnología, disminución del gasto social, desregulación financiera, apertura comercial e incremento de las tarifas de los servicios públicos, entre otros. 
En este artículo se conceptualizó al gobierno de Mauricio Macri como una "nueva derecha" democrática, pero que muestra una inclinación permanente a producir hechos que disminuyen la calidad institucional de la democracia; dispuesta discursivamente, pero no en la práctica, a marcar diferencias económicas con la derecha noventista y socialmente no inclusiva. Cada ciclo de la historia genera sus propios conceptos y los dota de sentido. Complejas y multidimensionales fueron las circunstancias que nos muestran a una derecha, que apartada del imaginario colectivo latinoamericano, deja de esconder sus ambiciones y se coloca en el centro de la escena política argentina, con un adjetivo adosado "nueva".

Esta nueva derecha presenta diferencias con las viejas, en tanto ha logrado despegarse de las tradiciones nacionalistas y más conservadoras y lo ha dejado claro en términos discursivos. La reciente emergencia programática de la derecha está en gran parte vinculada a su capacidad para distanciarse del proyecto de modernización conservadora defendido durante los años '80 y '90. Siguiendo a Pablo Stefanoni (2014), el hecho de que esta nueva derecha no tenga abiertamente en su agenda propuestas reprivatizadoras y a veces incluso compita con los gobiernos progresistas por las propuestas de mayor inclusión social, da cuenta de un clima de época particular.

Aun así, las ideas de la sociedad, del individuo, de la economía, de los derechos humanos, del papel del Estado, de la región, y de los vínculos internacionales expresan ciertas imágenes que hunden sus raíces en la historia argentina y que atraviesan la década menemista, el desafío de las administraciones kirchneristas y que llegan hasta nuestros días. En tanto esta nueva derecha ha adoptado una política exterior enmarcada en la globalización, "desideologizada” y pragmática; basada en el regionalismo abierto y en la promoción del sector privado y la inversión extranjera directa; y sustentada en reformas estructurales internar para flexibilizar los mercados de trabajo y lograr la liberalización financiera, la austeridad fiscal y la eliminación progresiva de barreras arancelarias y no arancelarias, se podría decir que existe una alineación con el orden liberal y que, en este ámbito, no representa un cambio estructural en relación a la vieja derecha.

La premisa que inspiró y recorrió este trabajo es que la asunción de Mauricio Macri derivó en un cambio de rumbo en la estrategia de desarrollo elegida y, por ende, en las medidas de política exterior tomadas. En este sentido, el cambio de lógica de Cambiemos involucró un viraje profundo en el modelo de desarrollo que había llevado adelante la administración anterior, así como también modificaciones importantes en la agenda y las alianzas políticas.

En términos ideales, el modelo de desarrollo ortodoxo sostiene que las políticas domésticas deben ser coherentes y acoplarse con las directrices de la estrategia 
liberal de inserción internacional, teniendo en cuenta las características del contexto externo (Actis, Lorenzini, \& Zelicovich, 2017). Todas le medidas mencionadas anteriormente constituyen decisiones compatibles con el modelo de desarrollo ortodoxo, su consiguiente estrategia liberal de inserción internacional y su asociación con los gobiernos de derecha.

En vinculación directa, la política exterior evidenció un claro giro que se ve plasmado en el acercamiento de Argentina a los países europeos y el intento de concretar el acuerdo UE-Mercosur; la participación en el Foro Económico Mundial en Davos después de 10 años de ausencia; el auspicio de la Undécima Conferencia Ministerial de la Organización Mundial del Comercio, en diciembre de 2017; la designación para ejercer la presidencia del G20 y para ser la sede de su reunión anual del año 2018; la solicitud de la nueva administración para ingresar a la OCDE; el pago de deuda no reestructurada; el retorno a los préstamos del FMI con un programa stand-by de 36 meses; el intento de reconfigurar el Mercosur a la luz de un modelo de inserción internacional centrado en las agendas económicas y comerciales y en base a las ideas de la flexibilidad y la previsibilidad; el mayor acercamiento con la Alianza Pacifico, modelo de regionalismo a seguir; y el establecimiento de un nuevo lazo de cooperación con China, reflejado principalmente en la firma de 30 acuerdos de comercio e inversión y en la participación de Mauricio Macri en la Cumbre de "la Franja y la Ruta para la Cooperación Internacional”.

A partir del modelo de desarrollo elegido, esta nueva derecha generó un cambio de $180^{\circ}$ en la política exterior. Y si bien su estrategia se reflejó de una manera atenuada en todos los discursos, estos acontecimientos no hacen sino confirmar la hipótesis de investigación presentada en el primer apartado de este trabajo, la cual afirmaba que la llegada al poder en Argentina de una "nueva derecha" genera modificaciones en la política exterior, cuyas principales manifestaciones son un nuevo posicionamiento ideológico, un claro giro primermundista y la consideración de la agenda externa como una especie de instrumento para lograr la transición hacia una economía globalizada. Además, estas modificaciones marcan una creciente articulación entre política doméstica y política exterior, lo que refuerza los ya consolidados enfoques académicos que califican a la política exterior como "interméstica", destacando la necesaria interacción entre los ámbitos domésticos y sistémicos como base de la acción externa de los Estados.

\section{Referencias bibliográficas}


Actis, E., Lorenzini, M.E., \& Zelicovich, J. (2017). La vinculación entre modelo de desarrollo y estrategia de inserción en la Argentina democrática (1983-2011) Studia Politicæ, 41, pp. 105-135. Recuperado de: http://revistas.bibdigital.uccor.edu.ar/index.php/Prueba2/article/view/1282/1225 Arditi, B. (2009). El giro a la izquierda en América Latina: ¿una política post-liberal? Ciências Sociais Unisin, 45 (3).

Argentina ingresa como miembro pleno a la Agencia de Energía Nuclear. (2017). MercoPress. Recuperado de: https://es.mercopress.com/2017/05/23/argentinaingresa-como-miembro-pleno-a-la-agencia-de-energia-nuclear

Argentina prioriza al Mercosur en su política exterior. (2016). Sputnik News. Recuperado de: https://mundo.sputniknews.com/economia/201606011060308798argentina-Mercosur /

Argentina se abre al mundo en el primer año de Macri. (2016). Sputnik News. Recuperado de: https://mundo.sputniknews.com/politica/201612091065442430america-latina-macri/

Argentina vuelve a Davos. (2016). Resumen del Sur. Recuperado de: http://www.resumendelsur.com/2016/01/12/argentina-vuelve-a-davos/ Argentina y China: estos son los principales acuerdos firmados. (2018). Ámbito. Recuperado de: https://www.ambito.com/argentina-y-china-estos-son-losprincipales-acuerdos-firmados-n5002891

Asamblea de Pequeños y Medianos Empresarios. (2018). Atender la emergencia de las Mipymes ante la caída de la economía real. Recuperado de: http://www.apyme.org.ar/documento-presentado-a-la-secretaria-deemprendedores-y-pymes/

Asiain, A. (2018). La nueva derecha. Página 12. Recuperado de https://www.pagina12.com.ar/119001-la-nueva-derecha

Atkins, P. (1991). América Latina en el Sistema Político Internacional. Buenos Aires: GEL.

Banco Central de la República Argentina. (2018). Resultado del Relevamiento de Expectativas de Mercado. Recuperado de http://www.bcra.gob.ar/Pdfs/PublicacionesEstadisticas/REM181129\%20Res ultado s\%20web.pdf

Bobbio, N. (1995). Derecha e izquierda: razones y significados de una distinción política. Madrid: Taurus.

Bohoslavsky, E. \& Morresi, S. (2016). El partido PRO y el triunfo de la nueva derecha en Argentina. Amérique Latine, 32. Recuperado de: https://journals.openedition.org/alhim/5619 
Busso, A. (2016). Los desafíos de América de Sur frente a Estados Unidos en la segunda década del siglo XXI. En R, Duarte Fernandes Dos Passos \& A, Fuccille (organizadores), Visões do Sul: crise e transformações do sistema internacional Volume 1. Marília: Cultura Acadêmica. Recuperado de: https://www.marilia.unesp.br/Home/Publicacoes/visoes-do-sul_vol.1-ebook.pdf Busso, A. (coord.). (2016). Modelos de desarrollo e inserción internacional: aportes para el análisis de la política exterior argentina desde la redemocratización 19832011. Rosario: UNR Editora. Recuperado de: https://rephip.unr.edu.ar/bitstream/handle/2133/7602/0.pdf?sequence=3\&isAllow $\mathrm{ed}=\mathrm{y}$

Busso, A. (2017a). El rol de los Estados Unidos en el diseño de política exterior del gobierno de Mauricio Macri. Conceptos básicos para su análisis. Anuario en Relaciones Internacionales, pp. 1-15. La Plata. Recuperado de: http://hdl.handle.net/2133/9137

Busso, A. (2017b). Mauricio Macri y el giro en la política exterior. Análisis y reflexiones. Ponencia presentada en el XIII Congreso de la Sociedad Argentina de Análisis Político, Universidad Torcuato Di Tella, agosto.

Busso, A. (2018). Política exterior y cambio cultural en el gobierno de Mauricio Macri. En Esteban Iglesias y Juan Lucca (coords.) La Argentina de Cambiemos. UNR Editora. Recuperado de: https://rephip.unr.edu.ar/handle/2133/15433

Busso, A., \& Zelicovich, J. (2016). El gobierno de Mauricio Macri y la integración regional: ¿desde el MERCOSUR a la Alianza del Pacífico? Conjuntura Austral. Universidade do Rio Grande do Sul. Recuperado de: http://hdl.handle.net/11336/61003

Calvo Salazar, C. (2009). La "nueva" izquierda latinoamericana: características y retos futuros. Reflexiones, 88 (1). Recuperado de: http://www.redalyc.org/articulo.oa?id=72912559004

Castañeda, J. (2006). Latin America's Left Turn. Foreign Affairs, 85 (3). Recuperado de: https://www.foreignaffairs.com/articles/south-america/2006-05-01/latinamericas-left-turn

Castaño, F. (2017). Algunas consideraciones sobre la política exterior argentina luego del ejercicio de Malcorra como canciller. Boletín Informativo $\mathrm{n}^{\circ} 60$. Departamento de América Latina y el Caribe (IRI-UNLP), La Plata. Recuperado de: http://www.iri.edu.ar/wp-content/uploads/2017/07/bo-alatina-60-artcasta\%C3\%B1o.pdf

Caparrós, M. (2018). La Argentina otra vez de nuevo. The New York Times. Recuperado de: https://www.nytimes.com/es/2018/05/11/opinion-caparrosargentina-crisis-fmi-macri/ 
Carmona, G. (2018). Macri y los riesgos del laberinto brasileño. Página 12. Recuperado de: https://www.pagina12.com.ar/149033-macri-y-los-riesgos-dellaberinto-brasileno

Casa Rosada. www.casarosada.gob.ar. Recuperado de: https://www.casarosada.gob.ar/slider-principal/35845-el-presidente-mauriciomacri-recibio-a-barack-obama

Chávez, D., Garavito Rodríguez, C. \& Barret, P. (eds.). (2005). La nueva izquierda en América Latina: sus orígenes y trayectoria futura. Madrid: La Catarata

CIFRA - FLACSO. (2016). La naturaleza política y económica de la Alianza Cambiemos. Recuperado

de: http://www.centrocifra.org.ar/publicacion.php?pid=92

Comisión Estado y Administración Pública en el Proyecto Nacional. (2017). El Estado que Cambiemos pretende: limitaciones e impacto regresivo. Buenos Aires. Recuperado de: http://equiposweb.com.ar/web/wp-content/uploads/El-programade-Gesti\%C3\%B3n-P\%C3\%BAblica-Cambiemos.pdf

Cué, C. (2016). Obama llega a Argentina para consagrar el giro de Macri. El País. Recuperado de: https://elpais.com/internacional/2016/03/23/actualidad/1458730293_412564.html De criticar la alianza estratégica del kirchnerismo con China, Macri pasó a firmar más de 30 acuerdo con Xi Jinping. (2018). El Sol. Recuperado de: https://diarioelsol.com.ar/2018/12/03/de-criticar-la-alianza-estrategica-delkirchnerismo-con-china-macri-paso-a-firmar-mas-de-30-acuerdo-con-xi-jinping/ El-Erian, M. A. (2006). El ascenso de la derecha en América Latina. Nueva Sociedad. Recuperado de: http://nuso.org/articulo/el-ascenso-de-la-derecha-enamerica-latina/

El futuro del Mercosur, en manos de Jair Bolsonaro y Mauricio Macri. (2018). Sputnik News. Recuperado de: https://mundo.sputniknews.com/blogs/201812261084399723-como-bolsonaro-ymacri-influiran-en-Mercosur /

El Gobierno acepta el veto de Trump y da de baja las centrales nucleares de China y Rusia. (2018). Marca Política. Recuperado de: http://www.marcapolitica.com/2018/12/el-gobierno-acepta-el-veto-de-trumpy.html

Ester, B., Gómez Daza, A. (2018). ¿Existe una nueva derecha en América Latina? Centro Estratégico Latinoamericano de Geopolítica (CELAG). Recuperado de: https://www.celag.org/existe-una-nueva-derecha-america-latina/ 
Fondo Monetario Internacional. (2018). www.imf.org. Recuperado de: https://www.imf.org/es/News/Articles/2018/12/19/pr18485-argentina-imfexecutive-board-completes-second-review-under-stand-by-arrangement Franco, L. (2017). Argentina vuelve a financiarse con el FMI: Macri anunció el inicio de negociaciones para un préstamo. Ámbito. Recuperado de: https://www.ambito.com/argentina-vuelve-financiarse-el-fmi-macri-anuncio-elinicio-negociaciones-un-prestamo-n4020594

Frenkel, A. (2016). Muevan el mundo que me quiero subir: Política exterior e integración regional en el gobierno de Mauricio Macri. Informe de Coyuntura ORALC, No 2, pp. 16-29. Universidad de la República. Recuperado de: http://hdl.handle.net/11336/28986

Ganó Fulvio Pompeo: Renunció Malcorra y la reemplaza el vicecanciller de Ruckauf. (2017). La Política Online. Recuperado de: https://www.lapoliticaonline.com/nota/105796-gano-fulvio-pompeo-renunciomalcorra-y-la-reemplaza-el-vicecanciller-de-ruckauf/

Garretón, MA. (2006). Modelos y liderazgos en América Latina. Nueva Sociedad, 205. Recuperado de: http://nuso.org/articulo/modelos-y-liderazgos-en-americalatina/

Gilhodes, P. (2007). ¿América Latina: giro a la izquierda? Oasis, 13. Recuperado de: https://revistas.uexternado.edu.co/index.php/oasis/article/view/2446/2084

Giordano, V. (2014). ¿Qué hay de nuevo en las «nuevas derechas»?. Nueva Sociedad, 254. Recuperado de: http://nuso.org/articulo/que-hay-de-nuevo-en-lasnuevas-derechas/

Granovsky, M. (2016). ¿Derecha democrática? Página 12. Recuperado de: https://www.pagina12.com.ar/57262-derecha-democratica

Hua, L. (2017). Las relaciones económicas y comerciales entre China y Argentina en la era de Mauricio Macri. Relaciones Internacionales, 53, pp. 229-237. Universidad Nacional de La Plata. Recuperado de: https://doi.org/10.24215/23142766e020

Instituto Nacional de Estadística y Censos. www.indec.gob.ar. Informes Técnicos vol. $2 \mathrm{n}^{\circ} 188$. Condiciones de vida vol. $2 \mathrm{n}^{\mathrm{o}} 12$ Incidencia de la pobreza y la indigencia en 31 aglomerados urbanos. Primer semestre de 2018 Recuperado de: https://www.indec.gob.ar/uploads/informesdeprensa/eph_pobreza_01_18.pdf Lambert, R. (2016). Las tensiones del poder. Le Monde Diplomatique. Recuperado de: https://www.eldiplo.org/199-america-latina-gira-a-la-derecha/las-tensionesdel-poder/

Lee Wynne, P. (2016). Macri vuelve al mundo de la élite internacional. Sputnik News.

Recuperado de: 
https://mundo.sputniknews.com/firmas/201601221055976799-macri-vuelvemundo-elite/

Leiras, M., Malamud, A. \& Stefanoni, P. (2016). ¿Por qué retrocede la izquierda? Ciudad Autónoma de Buenos Aires: Capital Intelectual.

Los cruces de Macri con Maduro y sus críticas al régimen chavista (2019). Perfil. Recuperado de: https://www.perfil.com/noticias/politica/como-mauricio-macriendurecio-su-postura-frente-a-venezuela.phtml

Macri, M. (2015). Palabras del Presidente Mauricio Macri en su discurso de asunción. Disponible en: https://www.youtube.com/watch?v=mb_TQniDsRs

Macri, M. (2015). Palabras de Mauricio Macri en Argentina Debate: Debate Presidencial. Disponibles en: https://www.youtube.com/watch?v=bkK8iI2qZVg

Macri, M. (2015). Palabras de Mauricio Macri en Argentina Debate, Ballotage. Disponible en: https://www.youtube.com/watch?v=_k7AAednkHM.

Macri, M. (2016). Palabras del Presidente Mauricio Macri en la apertura de Sesiones Ordinarias del Congreso Nacional. Disponible en: https://www.youtube.com/watch?v=8uV309Ug5AU.

Macri, M. (2018). Palabras del Presidente Mauricio Macri en la apertura del $136^{\circ}$ período de sesiones ordinarias del Congreso Nacional. Disponible en: https://www.youtube.com/watch?v=MRipG14aV4U.

Macri, M. (2018). El Presidente Mauricio Macri anuncia que la Argentina vuelve al FMI: el país en crisis. Disponible en: https://www.youtube.com/watch?v=uvWNFI9-IZY

Mauricio Macri inauguró la conferencia de la OMC: "La nueva etapa de la Argentina despierta mucho entusiasmo. (2017). La Nación. Recuperado de: https://www.lanacion.com.ar/2090139-mauricio-macri-en-la-conferencia-de-laomc

Macri sobre OCDE: "todo el mundo acepta el ingreso de la Argentina. (2018). Ámbito. Recuperado de: https://www.ambito.com/macri-ocde-todo-el-mundoacepta-el-ingreso-la-argentina-n5002788

Macri y la corrupción: trece casos polémicos que despertaron sospechas. (2018). La Voz. Recuperado de: https://www.lavoz.com.ar/politica/macri-y-la-corrupciontrece-casos-polemicos-que-despertaron-sospechas

Macri agradeció el apoyo de Estados Unidos al recibir a Donald Trump. (2018). Telam. Recuperado de: https://www.telam.com.ar/notas/201811/310707-macrirecibe-a-trump-en-casa-rosada-antes-del-inicio-de-la-cumbre-del-g20.html

Macri: "Argentina no ve la presencia de China como una amenaza, sino como una oportunidad". (2018) Telam. Recuperado de: 
https://www.telam.com.ar/notas/201812/311139-macri-argentina-no-ve-lapresencia-de-china-como-una-amenaza-sino-como-una-oportunidad.html Macri: "Nuestra inteligencia es tener buenas relaciones con todos los países". (2018). Telam. Recuperado de: http://www.telam.com.ar/notas/201812/311457-macrinuestra-inteligencia-es-tener-buenas-relaciones-con-todos-los-paises.html

Malcorra, S. (2017). Entrevista que le realizó C. Pagni a Susana Malcorra. Disponible en: https://www.youtube.com/watch?v=c35IWzovlV8

Malcorra, S. (2017). La Canciller Susana Malcorra anunció en conferencia de prensa junto a Mauricio Macri y Marcos Peña, que renuncia a su posición de canciller por cuestiones personales. Disponible en: https://www.youtube.com/watch?v=6eGkpmW 8JJU

Ministerio de Relaciones Exteriores y Culto de la República Argentina. (2016). www.cancilleria.gob.ar. Recuperado de: https://www.cancilleria.gob.ar/es/argentina-presidira-el-g20-en-2018 Ministerio de Relaciones Exteriores y Culto de la República Argentina. (2017). www.cancilleria.gob.ar. Recuperado de: https://www.cancilleria.gob.ar/es/actualidad/boletin/argentina-sede-de-la-11aconferencia-ministerial-de-la-omc

Ministerio de Relaciones Exteriores y Culto de la República Argentina. (2018). www.cancilleria.gob.ar. https://www.cancilleria.gob.ar/es/actualidad/noticias/declaracion-conjunta-entrela-republica-popular-china-y-la-republica-argentina Miranda, R. (2005). La política exterior argentina como objeto de estudio. Un enfoque, algunas pistas. Ponencia. Jornadas sobre Prospectivas y perspectivas de nuestra política exterior. La Plata.

Mohamed A. (2016). El ascenso de la derecha en América Latina. Nueva Sociedad. Recuperado de: http://nuso.org/articulo/el-ascenso-de-la-derecha-en-americalatina/

Moreira, C., Raus, D., \& Gómez Leyton, J. (2008) La nueva política en América Latina. Rupturas y Continuidades. Montevideo: Ediciones Trilce.

Morresi, S. (2008). La nueva derecha argentina: la democracia sin política. Buenos Aires: Universidad Nacional de General Sarmiento.

Natanson, J. (2017). El macrismo no es un golpe de suerte. Página 12. Recuperado de: https://www.pagina12.com.ar/56997-el-macrismo-no-es-un-golpe-de-suerte Natanson, J. (2018). ¿Por qué? Ciudad Autónoma de Buenos Aires: Siglo Veintiuno. Oviedo, E. (2017). Alternancia política y relaciones económicas con China. Una mirada de los capitales chinos ante el cambio político. IX Congreso Latinoamericano de Ciencia Política, Universidad de la República, Uruguay. 
Pedrueza Carranza, I. (2010). El Giro latinoamericano, panorama de una década: Una nueva geopolítica, corrientes, cambios y permanencias. XIV Encuentro de Latinoamericanistas Españoles. Santiago de Compostela, España: Universidad de Santiago de Compostela. Recuperado de: https://halshs.archivesouvertes.fr/halshs-00531197/document

Pereyra Doval, M.G. (2017). Política exterior y modelos de desarrollo. Argentina y Brasil en perspectiva comparada (1930-2010). Apuntes, 80. Recuperado de: http://revistas.up.edu.pe/index.php/apuntes/article/view/784/868

Pettinari, N. (2018). A tres años de la nueva política exterior argentina. La Capital. Recuperado de: https://www.lacapital.com.ar/opinion/a-tres-anos-la-nuevapolitica-exterior-argentina-n1673912.html

Pompeo, F. (2015). La política exterior que propone Macri. Clarín. Recuperado de: https://www.clarin.com/opinion/onu-papa_francisco-mercosurderechos_humanos_0_SJj9EGYDQl.html

Rapoport, M. (2017). De las relaciones entre Argentina y Estados Unidos. Foreign Affairs Latinoamérica. Abril. Recuperado de: http://revistafal.com/delasrelaciones-entre-argentina-y-estados-unidos/

Riesco Perez, S. (2018). Latinoamérica se hace de derechas. Rtve. Recuperado de: http://www.rtve.es/noticias/20181030/latinoamerica-se-hace-

derechas/1829180.shtml

Rivas Molina, F. (2018). Argentina pide un rescate al FMI. El País. Recuperado de: https://elpais.com/internacional/2018/05/08/actualidad/1525792674_832004.html Rovira Kaltwasser, C. (2014). La derecha en América Latina y su lucha contra la adversidad. Nueva Sociedad, 264. Recuperado de: http://nuso.org/articulo/laderecha-en-america-latina-y-su-lucha-contra-la-adversidad/

Sader, E. (2009). El Nuevo topo. Los caminos de la izquierda latinoamericana. Buenos Aires: Siglo Veintiuno.

Sader, E. (2018). La nueva derecha latinoamericana. Página 12. Recuperado de https://www.pagina12.com.ar/155477-la-nueva-derecha-latinoamericana

Santander, S. (2009). El 'giro a la izquierda' en América Latina.: Fragmentación y recomposición de la geopolítica regional. Cuadernos sobre Relaciones Internacionales, Regionalismo y Desarrollo, 4 (7). Recuperado de: http://www.saber.ula.ve/bitstream/handle/123456789/30712/articulo1.pdf;jsessio nid=CBF928BD39C815875A6AD08679AF56AF?sequence $=1$

Secretaría de Trabajo y Empleo Ministerio de Producción y Trabajo. www.trabajo.gob.ar. Situación y evolución del trabajo asalariado en el sector privado

en

2018.

Recuperado 
de:http://www.trabajo.gob.ar/downloads/estadisticas/asalariadosectorprivado/asal ariadossectorprivado_1812_informe.pdf

Soreanu Pecequilo, C. (2016). O Reposicionamento Estratégico dos Estados Unidos na América do Sul. En R, Duarte Fernandes Dos Passos \& A, Fuccille (eds.), Visões do Sul: crise e transformações do sistema internacional Volume 1. Marília: Cultura Acadêmica.

Stefanoni, P. (2014). La lulización de la izquierda latinoamericana. Le Monde Diplomatique, edición especial: Fracturas en América Latina. Recuperado de: https://www.eldiplo.org/notas-web/la-lulizacion-de-la-izquierda-latinoamericana/ Stoessel, S. (2014). Giro a la izquierda en la América Latina del siglo XXI. Revisitando los debates académicos. Polis, 34. Recuperado de: https://journals.openedition.org/polis/10453?lang=pt

Teijeiro, M. (2018). Entendiendo el giro a la derecha de América Latina. Infobae. Recuperado de: https://www.infobae.com/opinion/2018/11/09/la-derechizacionlatinoamericana/

Traverso, E. (2018). Las nuevas caras de la derecha. Buenos Aires: Siglo Veintiuno Vásquez, F. (2016). La crisis del posneoliberalismo. Le Monde Diplomatique, 202. Vommaro, G (2015). Mundo Pro. Anatomía de un partido fabricado para ganar. Ciudad Autónoma de Buenos Aires: Planeta

Vommaro, G. (2016). Unir a los argentinos: El proyecto de "país normal" de la nueva centroderecha en Argentina. Nueva Sociedad, 261. Recuperado de: http://nuso.org/media/articles/downloads/COY1_Vommaro_261.pdf

Vommaro, G. (2017). La centroderecha y el «cambio cultural» argentino. Nueva Sociedad, 270. Recuperado de: http://nuso.org/articulo/la-centroderecha-y-elcambio-cultural-argentino/

Vommaro, G. (2017). La larga marcha de cambiemos. La construcción silenciosa de un proyecto de poder. Ciudad Autónoma de Buenos Aires: Siglo Veintiuno.

Vommaro, G., \& Gené, M. (2017). Argentina: el año de Cambiemos. Revista de Ciencia Política, 37 (2), pp. 231-253. Recuperado de: http://www.revistacienciapolitica.cl/index.php/rcp/article/view/345/64

World Trade Organization. www.wto.org. Recuperado de: https://www.wto.org/spanish/res_s/statis_s/merch_trade_stat_s.htm 